DOI 10.26886/2523-6938.1(2)2018.3

UDC 616.833.24-008:615.322(075.9)

\title{
PHYTOSORTS «FAMILY HEALTH» IN OPTIMIZING THE REHABILITATION OF PATIENTS WITH VERTEBROGENIC PAIN SYNDROMES
}

\section{* I. I. Pavlusenko, Doctor of Medicine and Philosophy, Professor, \\ * M. A. Makeeva, Senior Researcher, Associate Professor,}
${ }^{* *}$ A. A. Zhernovenkov, doctor-rheumatologist of the highest category, *** V. I. Pavlusenko

*European University of Functional Medicine, Ukraine, Kiev ${ }^{* *}$ Kharkov Clinical Hospital for Railway Transport No. 2, Ukraine, Kharkov ${ }^{* * *}$ A. A. Bogomolets National Medical University, Ukraine, Kiev

The subject of the study is the establishment of the value of the effectiveness of the application of a complex of phytosbores obtained with the help of bioenergetic technologies in patients with vertebral pathology of the spine. The use of therapy using the standard treatment regimen and the integrated use of 5 phytosolves "Family Health" obtained with the help of bioenergetic technologies is substantiated. For this purpose, 45 patients with pain syndrome of cervicothoracic and lumbosacral localization were examined, who, in the course of the planned course of in-patient rehabilitation, along with the standard treatment scheme, received a phytocomplex from 5 phytospores. The control group was also made up of 45 patients with the presence of a similar pain syndrome without using a complex of phytospores in the rehabilitation process. Complex therapy from phytospores was taken internally. Patients of the main group after completion of the course of treatment noted significant subjective improvement, correlating with the results of clinical objective examination 
and with the data of scales. The advantage of this method is the absence of side effects and complications, the possibility of using both inpatient and outpatient settings, both during the planned course of treatment, and to achieve a supportive effect during periods of remission.

Key words: phytotherapy, phytospora complex, phytotherapy, phytospora complex, cervicalgia, osteochondrosis, lower back pain.

*Доктор медицины и фрилософии, профрессор Павлусенко И. И., ${ }^{*}$ старший научный сотрудник, доцент Макеева М. А., "*врачревматолог высшей категории, Жерновенков А. А., *** Павлусенко В. И. Фитосборы «Здоровье семьи» в оптимизации реабилитации больных с вертеброгенными болевыми синдромами/ *Европейский университет фоункциональной медицины, Украина, Киев; **Харьковская клиническая больница на железнодорожном транспорте № 2, Украина, Харьков; ***Национальный медицинский университет им. Богомольца, Украина, Киев

Предметом исследования является установление значения эфрфективности применения комплекса фритосборов, полученных с помощью биоэнергетических технологий, у пациентов $c$ вертеброгенной патологией позвоночника. Обосновано применение терапии с использованием стандартной схемы лечения $и$ комплексного использования 5 фритосборов «Здоровье семьи» полученных с помощью биоэнергетических технологий. С этой целью обследовано 45 больных с болевым синдромом шейно-грудной и пояснично-крестцовой локализации, которые в процессе планового курса стационарной реабилитации, наряду с использованием стандартной схемы лечения получали фритокомплекс из 5 фитосборов. Контрольную группу составили также 45 пациентов с наличием аналогичного болевого синдрома без использования комплекса фитосборов в процессе реабилитации. Комплексная 
терапия из фритосборов принималась внутрь. Больные основной группы после завершения курса лечения отмечали значительное субъективное улучшение, коррелирующее с результатами клинического объективного осмотра и $c$ данными шкал. Достоинством данного метода является отсутствие побочных действий и осложнений, возможность применения как в стационаре, так и в амбулаторных условиях, как в процессе планового курса лечения, так и для достижения поддерживающего эффректа в периоды ремиссий.

Введение. Боль в спине является самой частой причиной обращения больных к невропатологу, терапевту, ревматологу, нейрохирургу. 10-20\% населения Земли ежегодно страдает от болевых синдромов в спине. В США боль в спине занимает первое место в структуре ревматических заболеваний среди взрослого населения. В Украине вертеброгенная патология и заболевания периферической нервной системы занимают второе место после цереброваскулярной патологии (показатели заболеваемости составляют 520 случаев на 100 тыс. населения) [1, с. 3 - 5]. В мире эта патология лидирует среди заболеваний, обусловливающих временную нетрудоспособность, а в Европе является второй по частоте обращений к неврологу и ревматологу. При этом только 40\% больных обращаются за медицинской помощью [2, с. 10 - 19]. Известно также, что у трети пациентов острая боль переходит в хроническую. Этот синдром имеет статус регистрационной категории в международной классификации болезней (МКБ-10) из-за его высокого уровня распространения и низкого процента установления конкретной анатомической причины боли [3, с. 17 - 20]. Боль в нижней части спины (БНС) определяется как боль, которая локализуется между XII 
парой ребер и ягодичными складками [4, с. $10 ; 5$, с. 31 ; 6, с. 39-44]. Синдрому свойственна значительная этиологическая и прогностическая гетерогенность, а также отсутствие общепринятой классификации. Обычно БНС классифицируют по анатомическим и временным признакам (вертеброгенная и невертеброгенная, острая, подострая и хроническая боль), а также различают механическую и воспалительную; первичную и вторичную; специфическую и неспецифическую дорсалгии [1, с. 22-25; 3, с. 17-20]. Наиболее частые причины БНС:

1) вертеброгенные: остеохондроз позвоночника, протрузия диска, сакрализация, люмбализация, артроз межпозвоночных суставов, спинальный стеноз, нестабильность позвоночно-двигательных сегментов, спондилолистез, функциональные нарушения (блоки позвонков), остеопоротические переломы тел позвонков; спондилоартриты;

2) экстравертебральные: миофасциальный болевой синдром; проекционная боль при заболеваниях внутренних органов, психогенная боль [7, с. 3-6; 8, с. 22-23].

По длительности синдром БНС может быть острым, подострым и хроническим: острая боль длится до 6 недель, хроническая - более 12 недель. До 90 - 95\% всех случаев составляет первичный (механический) синдром, возникающий на фоне дисфункции мышечносвязочного аппарата, остеохондроза позвоночника, спондилоартроза и грыж межпозвонковых дисков. Механическая дорсалгия обычно возникает в возрасте 20-50 лет и более характерна для женщин. Пик болевых ощущений приходится на 35-45 лет, хотя первые признаки могут определяться еще в детском и подростковом возрасте - в связи со сколиотической осанкой, сколиозом и кифозом, а также 
доброкачественным гипермобильным синдромом [9, с. 43; 10, с. $134-$ 140].

У больных до 20 и старше 50 лет преобладает вторичный синдром боли в спине, характеризующийся хроническим течением и худшим прогнозом и возникающий на фоне различных врожденных аномалий позвоночника и суставов (spina bifida), спондилоартритов (болезнь Бехтерева, псориатический артрит, реактивные артриты и синдром Рейтера, ювенильный хронический артрит, недифференцированная спондилоартропатия), травм, туберкулеза или опухолей позвоночника (злокачественные - первичные и метастатические, доброкачественные - кисты и хондромы), инфекций (остеомиелит, эпидуральный абсцесс, дисцит, арахноидит, паравертебральные очаги), а также при болезни Педжета, болезни Шотермана-Мау (юношеской остеохондропатии), первичном гиперпаратиреозе, остеомаляции и остеопорозе, осложненном переломами позвонков. Вторичной является также дорсалгия, возникшая на фоне заболеваний мочеполовой системы (мочекаменная болезнь, нефрома, простатит и аденокарцинома предстательной железы, альгодисменорея, аднексит, эндометрит, эндометриоз, утероптоз, миомы и рак матки), болезней внутренних органов (язва или опухоль желудка, панкреатит, киста или опухоль поджелудочной железы, дивертикулит или опухоль кишечника, разрыв или расслоение брюшной аорты, варикозное расширение вен таза). Возможны и психогенные дорсалгии (при депрессии).

Известны 4 вида боли в спине: локальный, проекционный (рефлекторный), корешковый и мышечно-спастический [1, с. 31-35; 3, c. 17-20]. Наиболее распространенной причиной первичного вертеброгенного болевого синдрома, особенно у женщин 30-45 лет, является остеохондроз поясничного отдела позвоночника, результат дегенеративно-дистрофических изменений межпозвонковых дисков и 
мышечно-связочного аппарата позвоночно-двигательного сегмента. После 50 лет эпизоды острого болевого синдрома возникают реже.

В клинической практике для лечения болевых синдромов чаще используют нестероидные противовоспалительные препараты, противоотёчные средства, миорелаксанты, препараты для улучшения периферического кровотока, габапентин и прегабалин, витамины группы В $[6$, с. $39-44 ; 11$, с. $3-6 ; 12$, с. $5 ; 13$, с. $38-39 ; 14$, с. 55 - 57; с. 71-73].

До сих пор немногочисленны литературные данные об эффрективности применения фитотерапии при заболеваниях опорнодвигательного аппарата, избирательности подбора и адаптационных механизмах действия фитотерапии [15, с. 3].

Цель исследования - сравнительная характеристика эффрективности лечения пациентов с болью в нижней части спины при включении в схему реабилитации метода комплексного приёма 5 фитосборов «Здоровье семьи», полученных с помощью биоэнергетических технологий.

\section{Материал и методы исследования.}

Под нашим наблюдением находилось 90 пациентов с болевым синдромом шейно-грудной и пояснично-крестцовой локализации, которые были разделены на две группы. Первую составили 45 больных с вертеброгенными рефлекторными и корешковым синдромами с включением в общую схему лечения метода комплексного приёма 5 фитосборов «Здоровье семьи», полученных с помощью биоэнергетических технологий.

Использовались следующие фитосборы: для нормализации функций опорно-двигательной системы (№ 6); для нормализации периферического кровообращения (№ 14); фитосбор, содержащий природные салицилаты (противовоспалительный № 22); для 
нормализации функций периферической нервной системы (№ 29); для нормализации регенеративной и восстановительной функций организма (соединительная ткань № 30). Все фритосборы применялись нашими больными внутрь, в сухом виде, по 1/4 чайной ложки каждого сбора, друг за другом, запивая водой, за 20 мин до еды, 3 раза в день. Пациентам 2-й группы (также 45 обследованных) проводилось только медикаментозное лечение.

Программа обследования включала: подробный сбор жалоб больных, анамнез заболевания и жизни, клинико-неврологическое обследование, рентгенографию шейно-грудного и поясничнокрестцового отделов позвоночника, исследование с помощью шкал и опросников - визуальной аналоговой шкалы (ВАШ), опросника Роланда-Моррисона «Боль в нижней части спины и нарушение жизнедеятельности» [16, с. 92-97, с. 122-128].

Для достоверности полученных результатов материалы исследования обрабатывались методом математической статистики с помощью критериев Стьюдента.

\section{Результаты и их обсуждение}

Пациенты были в возрасте 30-75 лет, что позволило охватить все возрастные группы проявления болевого синдрома в спине, с длительностью заболевания от 5 дней. Анамнез заболевания составил в среднем 1 год, что позволяло судить о постепенном переходе неспецифического воспалительного процесса в хроническое рецедивирующее течение. Анализируя жалобы пациентов, мы обнаружили, что для больных обеих групп была характерна острая, стреляющая боль в спине в зависимости от стадии патологического процесса, с иррадиацией в конечности; чаще - по наружно-боковой поверхности предплечья или плеча в $41,5 \%$ случаев и в $58,5 \%$ случаев - по наружной или задней поверхности бедра, голени, внешней или 
внутренней поверхности ступни. Боль у большинства пациентов имела постоянный характер, резко ограничивала объем движений в позвоночнике и при незначительных движениях резко усиливалась.

Для оценки болевого синдрома мы использовали ВАШ от 1 до 10 см. В обеих группах пациенты оценивали болевой синдром как выраженный, острый (7-10 по ВАШ). По результатам наших исследований, наиболее частыми фракторами, на фоне которых возникал или обострялся болевой синдром у пациентов, были профессиональные нагрузки - 28,2\%, избыточная масса тела - 27,3\%, переохлаждение - 31,8\%, физические перегрузки, связанные с длительной вынужденной позой - 12,7\%. Следует отметить, что у 72,3\% обследованных причиной проявления или обострения боли в спине была комбинация двух и более фракторов риска. Анализируя результаты клинических наблюдений, можно утверждать, что клиническая картина болевого синдрома, независимо от причинных фракторов, была довольно идентичной. Главный пик заболеваемости в двух клинических группах приходился на возраст 35-45 лет, общими были провоцирующие фракторы, которые и приводили к обострению. Поэтому у пациентов обеих групп, в зависимости от стадии патологического процесса, клинический симптомокомплекс был похожим: он включал боли различной интенсивности (100\% больных с ощущением дискомфорта в спине); болезненность паравертебральных участков при пальпации; напряжение прямых мышц спины. Рефлекторные и корешковые синдромы были характерны для больных с остеохондрозом шейно-грудного и пояснично-крестцового отдела позвоночника (таблица 1).

Таблица 1

\section{Частота клинических симптомов у больных в клинических}




\begin{tabular}{|c|c|c|c|c|}
\hline \multirow[t]{2}{*}{$\begin{array}{c}\text { Симптомокомплекс до начала } \\
\text { лечения }\end{array}$} & \multicolumn{2}{|c|}{$\begin{array}{c}\text { Основная } \\
\text { группа }\end{array}$} & \multicolumn{2}{|c|}{ Контр. группа } \\
\hline & $\begin{array}{l}\text { Абс. } \\
\text { число }\end{array}$ & $\%$ & $\begin{array}{l}\text { Абс. } \\
\text { число }\end{array}$ & $\%$ \\
\hline Боль различной степени & 45 & 100 & 45 & 100 \\
\hline $\begin{array}{l}\text { Болезненность паравертебральных } \\
\text { точек при пальпации }\end{array}$ & 37 & 82,2 & 39 & 86,6 \\
\hline \multicolumn{5}{|l|}{ Мышечно-тонические симптомы: } \\
\hline напряжение прямых мышц спины & 41 & 91,1 & 40 & 88,8 \\
\hline уменьшение лордоза & 13 & 28,8 & 5 & 11,1 \\
\hline сколиоз & 14 & 31,1 & 15 & 33,3 \\
\hline $\begin{array}{ll}\text { ограничение } & \text { движений } \\
\text { позвоночнике } & \end{array}$ & 42 & 93,3 & 40 & 88,8 \\
\hline Симптомы корешкового натяжения & 44 & 97,7 & 42 & 93,3 \\
\hline $\begin{array}{l}\text { Повышение, снижение или } \\
\text { отсутствие рефрлексов }\end{array}$ & 43 & 95,5 & 42 & 93,3 \\
\hline Расстройства чувствительности & 40 & 88,8 & 36 & 86,6 \\
\hline
\end{tabular}

Поражение корешков часто характеризовалось сочетанием двигательных и чувствительных нарушений в зоне соответствующих дерма- и миотомов. Больные жаловались на ощущение онемения, покалывания, «ползания мурашек» на стороне поражения. Такие нарушения в конечностях, возникающие в зоне боли, были обнаружены у 34 больных с поясничным остеохондрозом и у 35 больных с шейно-грудной патологией. Гиперестезия отмечалась у 42 пациентов первой и у 39 пациентов второй группы с корешковым синдромом. Для больных обеих групп было характерно снижение болевой и тактильной чувствительности. Парестезии часто сочетались с гиперестезией. При исследовании чувствительности над 
болезненными вегетативными узлами у 22 больных первой группы и 17 пациентов второй группы наблюдались участки гиперпатии, гиперестезии или гипостезии, которые имели пятнистый контур и не всегда совпадали с зонами сегментарной иннервации.

Характерной чертой для обеих групп больных были вегетативные нарушения, которые проявлялись висцеро-сосудистыми и сопутствующими висцеро-висцеральными, висцеро-сенсорными изменениями. Висцеро-сосудистые нарушения характеризовались периодическими ощущениями жжения или похолодания, изменениями потоотделения, дермографизма. Висцеро-висцеральный синдром имел место у 19 пациентов с радикулярными нарушениями. Он проявлялся кардиалгиями (15 больных) - сжимающими болями в области верхушки сердца с сенестопатической окраской. При усилении болей в спине выраженность и длительность кардиальных нарушений нарастала.

В исследование позвоночника мы проводили рентгенографию в двух стандартных проекциях. Обращали внимание на выпрямленность поясничного лордоза, параллелизацию покровных пластин смежных тел позвонков, сужение межпозвоночной щели, уплотнение замыкательных покровных пластин тел смежных позвонков, расширение каудальных площадок тел позвонков, боковые и передние остеофиты, очаги обызвествления фиброзного кольца диска. При анализе данных рентгенологического обследования мы оценивали состояние позвоночника в целом и выраженность фризиологической кривизны.

У всех больных первой и второй групп выявлены различные признаки остеохондроза позвоночника: склероз замыкательных пластинок, сужение межпозвоночной щели, наличие передних и задних краевых разрастаний (остеофитов); а также присутствовали 
рентгенографические признаки остеохондроза пояснично- крестцового отдела позвоночника, деформирующего спондилеза, что клинически отображалось в виде радикулопатий.

Уровень нарушения жизнедеятельности в связи с болевым синдромом в спине мы оценивали с помощью шкалы РоландаМоррисона. Нарушения жизнедеятельности пациентов основой и контрольной групп до начала лечения были выраженными, составляли 7-17 баллов по шкале.

Пациенты обеих групп получали лечение согласно стандартной схеме: инъекционные и таблетированные формы нестероидных противовоспалительных средств, миорелаксанты, препараты пентоксифиллина, венотоники, витаминные препараты.

В реабилитации всех 100\% больных основой группы использовался метод комплексного приёма 5 фитосборов (№6, 14, 22, 29, 30) «Здоровье семьи», полученных с помощью биоэнергетических технологий.

Используемые фритосборы отличались рядом важных особенностей [15, с. 13 - 14]:

1) Эффрективное усвоение в организме - лекарственные растения перерабатываются с применением биоэнергетических технологий и используются в микронном измельчении, что способствует их быстрому всасыванию.

2) Органоспецифичность - травы подобраны по признакам действия на конкретный орган или систему, учитывается не только механизм действия трав, но и определённое их весовое соотношение, поскольку в разных весовых пропорциях травы имеют различный механизм действия, что приводит к повышению результата. 
3) Натуральность - травы используются в истинно натуральном виде, без добавления вспомогательных веществ.

4) Удобство применения - по желанию пациента фритосборы применяются в виде исходной сухой фрормы (как в нашем исследовании) или в виде водных настоев фитосборов.

5) Полное сохранение биологически активных веществ, аминокислот, микроэлементов, витаминов и других биологически активных компонентов лекарственных растений.

Используемые в нашем исследовании фитосборы обладали следующими механизмами действия [15, с.18, 22, 26, 30]:

1) Способствовали улучшению периферического кровообращения;

2) Регулировали функции периферической нервной системы;

3) Обладали антиоксидантным, антисклеротическим, венотоническим, противоспазматическим, анальгетизирующим действием;

4) Препятствовали развитию венозного застоя;

5) Способствовали уменьшению воспалительных реакций в организме, регулированию трофических процессов микроциркуляции в воспалённых участках;

6) Восстанавливали регенераторные и репаративные процессы в тканях;

7) Способствовали укреплению и регулированию обменных процессов в клетках соединительной ткани;

8) Потенцировали выведение продуктов метаболизма и токсических веществ из органов и тканей организма.

Все обследованные приём комплекса фитосборов «Здоровье семьи» переносили удовлетворительно, осложнений во время приёма, побочных реакций - в нашем исследовании не наблюдалось. 
Приём комплекса из 5 фитосборов «Здоровье семьи» у пациентов основной группы позволил уменьшить прием медикаментозных препаратов и сократить сроки их назначения.

По результатам нашего исследования у пациентов обеих групп значительно уменьшилась выраженность болевого синдрома, симптомов натяжения, болезненности паравертебральных точек. Выраженность болевого синдрома снизилась по ВАШ до 3-1 балла (таблица 2).

В среднем в основной группе выраженность болевого синдрома по ВАШ уменьшилась на 6 баллов, что составляет $77,9 \%$ от максимальной выраженности боли (10 баллов) до начала лечения; в контрольной группе - на 3 балла (на 47\% меньше по сравнению с больными, получавшими комплекс из 5 фитосборов «Здоровье семьи»).

Таблица 2

Выраженность болевого синдрома по ВАШ

\begin{tabular}{|l|c|c|c|c|}
\hline \multicolumn{1}{|c|}{$\begin{array}{c}\text { Симптомокомплекс до начала } \\
\text { лечения }\end{array}$} & \multicolumn{2}{|c|}{$\begin{array}{c}\text { Основная } \\
\text { группа }\end{array}$} & \multicolumn{2}{|c|}{ Контр. группа } \\
\cline { 2 - 6 } & $\begin{array}{c}\text { Абс. } \\
\text { число }\end{array}$ & $\begin{array}{l}\text { Aбс. } \\
\text { число }\end{array}$ & $\%$ \\
\hline $\begin{array}{l}\text { До начала лечения - выраженный } \\
\text { болевой синдром (7-10 баллов) }\end{array}$ & 45 & 100 & 45 & 100 \\
\hline $\begin{array}{l}\text { После проведенного лечения - } \\
\text { легкий болевой синдром (3 балла) }\end{array}$ & 17 & 37,7 & 38 & 84,4 \\
\hline $\begin{array}{l}\text { После проведенного лечения - } \\
\text { отсутствие болевого синдрома (0-1 } \\
\text { балл) }\end{array}$ & & 62,2 & 7 & 15,5 \\
\hline
\end{tabular}

Значительно улучшились показатели нарушения жизнедеятельности по шкале Роланда-Моррисона (таблица 3). 
Таблица 3

Выраженность нарушений жизнедеятельности по шкале РоландаМоррисона

\begin{tabular}{|l|c|c|c|c|}
\hline \multicolumn{1}{|c|}{ Период лечения } & \multicolumn{2}{|l|}{ Основая группа } & \multicolumn{2}{|c|}{ Контр. группа } \\
\cline { 2 - 6 } & $\begin{array}{c}\text { Абс. } \\
\text { число }\end{array}$ & $\%$ & $\begin{array}{l}\text { Абс. } \\
\text { число }\end{array}$ & $\%$ \\
\hline $\begin{array}{l}\text { До начала лечения - выраженные } \\
\text { (7-17 баллов) }\end{array}$ & 45 & 100 & 45 & 100 \\
\hline $\begin{array}{l}\text { После лечения - незначительные } \\
\text { или отсутствующие (менее 7 } \\
\text { баллов) }\end{array}$ & 40 & 88,8 & 23 & 15,5 \\
\hline
\end{tabular}

Выраженность нарушения жизнедеятельности у больных основой группы в среднем составляла 9,6 балла (53,6\% от максимально возможного количества баллов - 18). После пройденной терапии этот показатель составлял 11,9\%, что свидетельствовало о быстрой динамике восстановления функций на фоне приема комплекса из 5 фитосборов «Здоровье семьи». В контрольной группе положительная динамика после проведенного лечения была менее заметной показатели нарушения жизнедеятельности уменьшились с 52,8\% до $21,4 \%$, что на 9,5\% меньше по сравнению с показателями основой группы.

Также на фроне приема комплекса из 5 фитосборов «Здоровье семьи» у больных основой группы значительно уменьшились жалобы по вегетативным нарушениям, кардиалгиям, чего не отмечалось у больных контрольной группы.

\section{Выводы.}

1. Метод использования фритопрепаратов «Здоровье семьи» у больных с вертеброгенной патологией в нашем исследовании это индивидуально подобранный комплекс для данной группы 
из 5 фритосборов, который устраняет болевой синдром, улучшает объём движений, способствует скорейшей реабилитации.

2. Проведенное лечение, с одной стороны направлено на исходную причину заболевания и воздействует на опорнодвигательный аппарат в целом. С другой стороны, использование фитосборов «Здоровье семьи» предусматривает общее биоэнергетическое воздействие на организм с целью повышения процессов компенсации двигательных фрункций и периферического кровообращения.

3. Полученные результаты в основной и контрольной группам свидетельствуют, что использование метода комплексного приёма 5 фитосборов «Здоровье семьи» (в нашем исследовании - №№ 6, 14, 22, 29, 30) у изученного контингента больных обладает достаточно высокой терапевтической эффрективностью за счет выраженного биоэнергетического воздействия, позитивного влияния на степень интенсивности болевого синдрома (по визуальной аналоговой шкале) и достоверно улучшает показатели нарушения жизнедеятельности по шкале Роланда-Моррисона.

4. Предлагаемый комплекс фитосборов «Здоровье семьи» позволил уменьшить прием медикаментозных препаратов и сократить сроки их назначения, в конечном итоге способствует повышению качества жизни.

5. Достоинством данного метода комплексного приёма 5 фитосборов «Здоровье семьи» является отсутствие побочных действий и осложнений, возможность применения в перспективе как в стационаре, так и в амбулаторных условиях, 
как в процессе планового курса лечения, так и для достижения поддерживающего эфффекта в периоды ремиссий.

6. Метод приёма внутрь комплекса из 5 фитосборов «Здоровье семьи» показан практически всем больным, страдающим заболеваниями опорно-двигательного апарата для лечения, реабилитации и профилактики.

\section{תumepamypa:}

1. Дзяк Г. В., Викторов А. П., Гришина Е. И. Нестероидные противовоспалительные препараты. - К.: Морион, 1999. - 122 с.

2. Van Tulder M. V., Koeg B. W. Low back pain and sciatica // Clin. Evid. 2001. - Vol. 6. - P. 10-19.

3. Новые подходы к применению витаминов группы В в комплексном лечении заболеваний периферической нервной системы / Ю. И. Головченко, Т. Н. Калищук-Слободян, А. В. Клименко и др. // Междунар. неврол. журн. - 2007. - № 1. - С. 17-20.

4. Боженко Н. Л. Опыт лечения болевого синдрома в спине // Новости медицины и фрармации. - 2007. - № 17 (224). - С. 10.

5. Мазуренко О. Боль. Диагностика и лечение боли в спине: современные аспекты // Здоровье Украины. - 2008. - № 2 (183). C. 31 .

6. Вертеброгенні больові синдроми попереково-крижового відділу хребта та також їх лікування із застосуванням вітамінів групи B / С. М. Вінічук, В. В. Бедрій, П. П. Уніч та ін. // Укр. мед. часопис. 2007. - № 6 (62). - C. 39-44.

7. Проблема гострого болю в ревматологічній практиці: нові підходи до вирішення / О. В. Курята, Ф. Х. Хіжазі, Г. М. Алла, А. С. Легкобит // Новини медицини і фрармації. - 2006. - № 18 (200). - С. 3-6. 
8. Морозова О. Г. Гострий біль у спині: підходи до терапії // Здоров'я України. - 2007. - № 6/1. - С. 22-23.

9. Голик В. А., Мороз О. М. Лікування пацієнтів з болем у нижній частині спини // Здоров'я України. - 2007. - № 6/1. - С. 43.

10. Manek N., MacGregor A. J. Epidemiology of low back disoders // Curr. Opin. Rheumatol. - 2005. - Vol. 17 (2). - P. 134-140.

11. Нестероїдні протизапальні препарати - хто лідирує в сучасній клініці? / М. М. Козачок, М. М. Селюк, С. А. Бичкова, Н. Г. Бичкова // Новини медицини і фрармації. - 2008. - № 4 (235). - С. 3-6.

12. Колосова T. В. Застосування нестероїдних протизапальних засобів в неврологічній практиці //Новини медицини і фрармації.2007.- № 215. - C. 5.

13. Особенности ведения больных с хроническим вертеброгенным болевым синдромом пояснично-крестцовой локализации / A. B. Клименко, Ю. И. Головченко, Т. Н. Калищук-Слободян и др. // Здоровье Украины. - 2007. - № 2 (159). - С. 38-39.

14. Патогенез, методи дослідження та лікування больових синдромів: посібник / Є. Л. Мачерет, Г. М. Чуприна, О. Г. Морозова та ін. - Харків: Контраст, 2006. - 168 c.

15. Павлусенко И.И. Руководство по применению фритосборов. Харьков: Центр «Здоровье семьи», 2014. - 48 с.

16. Белова А. Н., Щепетова О. Н. Шкалы, тесты и опросники в медицинской реабилитации. - М.: Антидор, 2002. - 440 c.

\section{References:}

1. Dzyak, G. V., Viktorov, A. P., Grishina, Ye. I. (1999). Nesteroidnye protivovospalitelnye preparaty. K. Morion, 122.

2. Van Tulder, M. V., Koeg, B. W. (2001). Low back pain and sciatica. Clin. Evid. (6), 10-19. 
3. Golovchenko, Yu. I., Kalishchuk-Slobodyan, T. N., Klimenko, A. V. i dr. (2007). Novye podkhody $k$ primeneniyu vitaminov gruppy $\vee v$ kompleksnom lechenii zabolevaniy perifericheskoy nervnoy sistemy. Mezhdunar. nevrol. Zhurn, (1), 17-20.

4. Bozhenko, N. L. (2007). Opyt lecheniya bolevogo sindroma v spine. Novosti meditsiny i farmatsii, (17 (224), 10.

5. Mazurenko, O. (2008). Bol. Diagnostika i lechenie boli v spine: sovremennye aspekty. Zdorove Ukrainy, (2 (183)), 31.

6. Vinichuk, S. M., Bedriy, V. V., Unich P. P. ta in. (2007). Vertebrogenni bolovi sindromi poperekovo-krizhovogo viddilu khrebta ta takozh ïkh likuvannya iz zastosuvannyam vitaminiv grupi V. Ukr. med. Chasopis, (6 (62), 39-44.

7. Kuryata, O. V., Khizhazi, F. Kh., Alla, G. M., Legkobit, A. S. (2006). Problema gostrogo bolyu $\mathrm{v}$ revmatologichniy praktitsi: novi pidkhodi do virishennya. Novini meditsini i farmatsiï, (18 (200), 3-6.

8. Morozova, O. G. (2007). Gostriy bil u spini: pidkhodi do terapii. Zdorov'ya Ukraini, (6/1), 22-23.

9. Golik, V. A., Moroz, O. M. (2007). Likuvannya patsientiv z bolem u nizhniy chastini spini. Zdorov'ya Ukraïni, (6/1), 43.

10. Manek, N., MacGregor, A. J. (2005). Epidemiology of low back disoders. Curr. Opin. Rheumatol, (17 (2), 134-140.

11. Kozachok, M. M., Selyuk, M. M., Bichkova, S. A., Bichkova, N. G. (2008). Nesteroïdni protizapalni preparati - khto lidirue $v$ suchasniy klinitsi? Novini meditsini i farmatsiï, (4 (235), 3-6.

12. Kolosova, T. V. (2007) Zastosuvannya nesteroïdnikh protizapalnikh zasobiv $v$ nevrologichniy praktitsi. Novini meditsini $i$ farmatsiï, (215), 5.

13. Klimenko, A. V., Golovchenko, Yu. I., Kalishchuk-Slobodyan, T. N. i dr. (2007). Osobennosti vedeniya bolnykh s khronicheskim 
vertebrogennym bolevym sindromom poyasnichno-kresttsovoy lokalizatsii. Zdorove Ukrainy, (2 (159), 38-39.

14. Macheret, E. L., Chuprina, G. M., Morozova, O. G. ta in. (2006). Patogenez, metodi doslidzhennya ta likuvannya bolovikh sindromiv: posibnik. Kharkiv. Kontrast, 168.

15. Pavlusenko, I. I. (2014). Rukovodstvo po primeneniyu fitosborov. Xarkov. Tsentr «Zdorove semi», 48.

16. Belova, A. N., Shchepetova, O. N. (2002). Shkaly, testy $i$ oprosniki v meditsinskoy reabilitatsii. Moscow. Antidor, 440.

BIOENERGETICS IN MEDICINE AND BIOLOGY. - 2018. - 1(2). - p. 33-51 